Baseline

\title{
Levels, distributions and sources of veterinary antibiotics in the sediments of the Bohai Sea in China and surrounding estuaries
}

\author{
Xinghua Liu ${ }^{\text {a,c }}$, Haibo Zhang a,c,*, Lianzhen $\mathrm{Li}^{\mathrm{a}}$, Chuancheng Fu ${ }^{\mathrm{a}, \mathrm{c}}$, Chen $\mathrm{Tu}^{\mathrm{a}}$, Yujuan Huang ${ }^{\mathrm{b}}$, Longhua Wu ${ }^{\mathrm{b}, \mathrm{c}}$, \\ Jianhui Tang ${ }^{\mathrm{a}, \mathrm{c}}$, Yongming Luo ${ }^{\mathrm{a}, \mathrm{c}, *}$, Peter Christie ${ }^{\mathrm{b}}$ \\ a Key Laboratory of Coastal Environmental Processes and Ecological Remediation, Yantai Institute of Coastal Zone Research, Chinese Academy of Sciences, Yantai 264003, China \\ b Key Laboratory of Soil Environment and Pollution Remediation, Nanjing Institute of Soil Science, Chinese Academy of Sciences, Nanjing 210008, China \\ c University of Chinese Academy of Sciences, Beijing 100049, China
}

\section{A R T I C L E I N F O}

\section{Article history:}

Received 8 October 2015

Received in revised form 13 May 2016

Accepted 16 May 2016

Available online 28 May 2016

\section{Keywords:}

Emerging contaminants

Estuaries

Marine sediment

Risk assessment

Spatial distribution

Source apportionment

\begin{abstract}
A B S T R A C T
Veterinary antibiotics are emerging contaminants of concern. A total of 139 samples comprising 104 marine sediments and 35 estuarine sediments were collected from the Bohai Sea area and analyzed for seventeen antibiotics. The results reveal that the presence and concentration of antibiotics were generally higher in the estuaries than in the sea. The highest antibiotic concentration, $4695 \mu \mathrm{g} \mathrm{kg}{ }^{-1}$ of oxytetracycline, occurred in the estuarine sediment from Ziya New River. Bohai Bay and Laizhou Bay and the surrounding estuaries had higher concentrations of antibiotics. However, low levels of antibiotics detected were detected in Liaodong Bay in contrast to the high concentrations present in the surrounding estuaries. Spatial heterogeneity and principal component analysis suggest a large impact of terrestrial sources of the antibiotics contaminating the Bohai Sea. Risk quotients indicate that current levels of norfloxacin and oxytetracycline might be potentially hazardous to sensitive biota both in the Bohai Sea and in its surrounding estuaries.
\end{abstract}

(C) 2016 Published by Elsevier Ltd.
Veterinary antibiotics are emerging contaminants in both terrestrial and marine environments of increasing concern in recent years. Antibiotic residues in the environment are mainly derived from the extensive and long-term use of both human and veterinary medicines (Kümmerer, 2009). China leads the world in volume of antibiotic production and usage. Although some antibiotics have been regulated in animal feeds since 1989, the amount used was up to 92,700 tonnes in 2013 (Zhang et al., 2015b). Antibiotics are poorly adsorbed in the gut of the animals and as much as $90 \%$ of each dose is excreted in urine and $75 \%$ remains unchanged in the feces (Halling-Sørensen, 2000; Sarmah et al., 2006). Thus, a substantial proportion of administered antibiotics enters the environment through wastewater discharge and the land application of manures and sludges, eventually entering the marine environment by riverine input (Jia et al., 2011; Zhang et al., 2012; Zou et al., 2011) and sewage discharge (Gulkowska et al., 2007; Minh et al., 2009). It was reported that over thirty-five main rivers surrounding the Bohai Sea were severely polluted (Jun, 2007; Mao et al., 2009) and transported $36 \%$ of wastewaters and $47 \%$ of the solid pollutants to the Bohai Sea (Wang and Wang, 2007). Increasing use of antibiotics in aquaculture is another important source for the marine environment (Jia et al., 2011; Kümmerer, 2009; Martins et al., 2008; Minh et al.,

\footnotetext{
* Corresponding authors at: Yantai Institute of Coastal Zone Research, Chinese Academy of Sciences, Yantai 264003, China.

E-mail addresses: hbzhang@yic.ac.cn (H. Zhang), ymluo@yic.ac.cn (Y. Luo).
}

2009; Wille et al., 2010; Xu et al., 2007; Zou et al., 2011). The Bohai Sea is the only continental sea in China and has a low exchange rate of seawater, resulting in the long-term residence of pollutants in the sea (Li et al., 2014). Several studies have indicated the presence of high antibiotic contamination in the surface waters of the Bohai Sea (Zhang et al., 2013; Zhang et al., 2012). More than ten antibiotics were found at high detectable frequencies in the surface waters with maximum concentrations of roxithromycin (RTM), trimethoprim (TMP) and sulfamethoxazole (SMX) of $0.63,0.33$ and $0.077 \mu \mathrm{g} \mathrm{L} \mathrm{L}^{-1}$, respectively (Zhang et al., 2012; Zou et al., 2011). Many antibiotics have a high $\mathrm{K}_{d}$ value and are liable to be adsorbed by solid particles such as sediments (Wang and Wang, 2015).

Antibiotic residues in the marine sediments are also very important in terms of the fate of antibiotics in the marine environment and their ecological risks (Bu et al., 2013; Eguchi et al., 2004; Kümmerer, 2004). However, until now to our knowledge no available data have been reported regarding the antibiotic contamination in the sediments of the Bohai Sea. The purposes of the present study were therefore to fill the knowledge gap regarding the occurrence of antibiotics in the marine and estuarine sediments and to identify the potential sources of the antibiotics in this area.

Surface sediment (0-10 cm depth) samples were collected using a stainless steel sediment sampler from 139 sites comprising 104 marine sites and 35 estuarine sites on one research cruise covering the whole Bohai Sea from August 11 to September 5, 2014 (Fig. 1). All the samples 

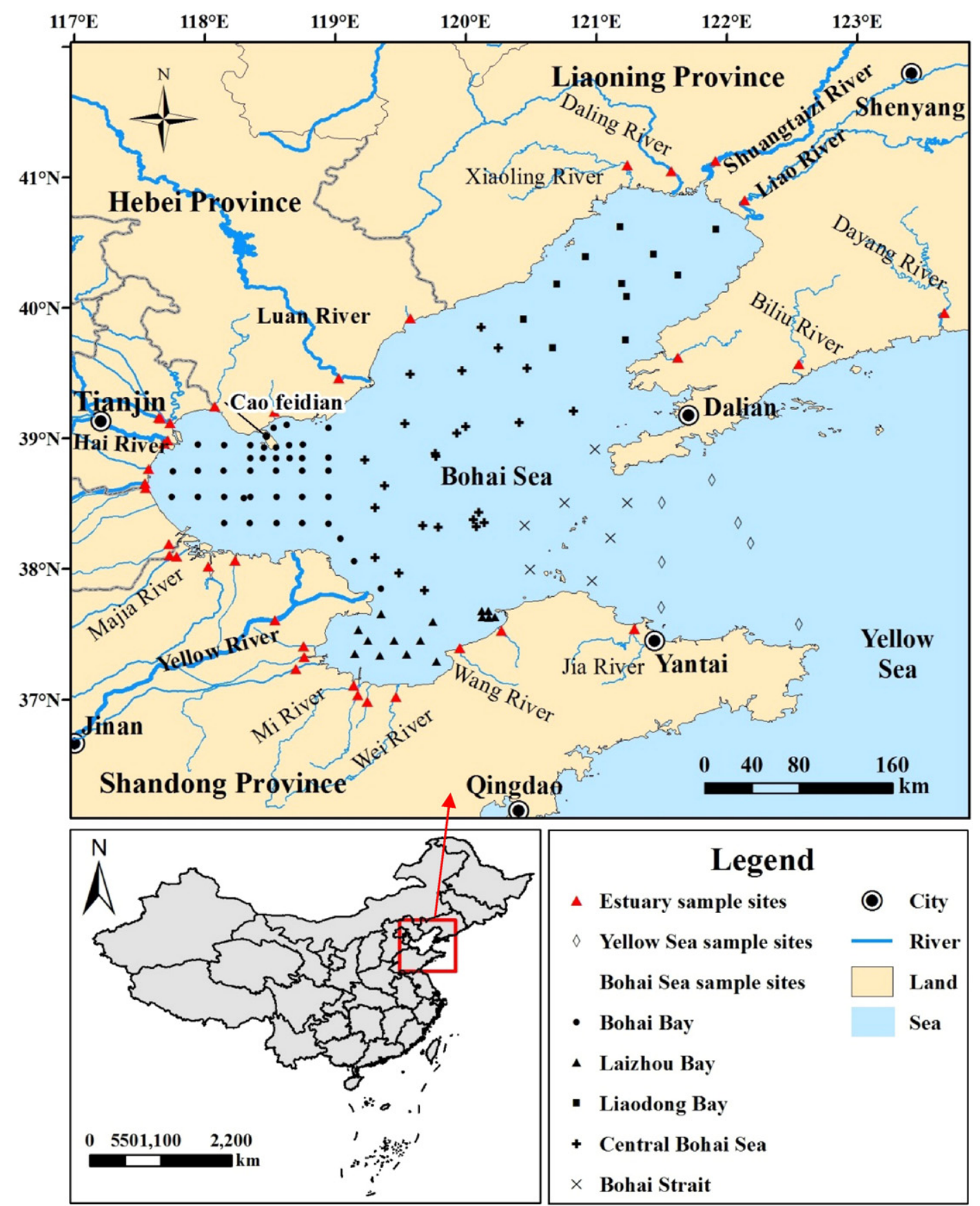

\section{Legend}

$\triangle$ Estuary sample sites

$\diamond$ Yellow Sea sample sites

Bohai Sea sample sites

- Bohai Bay

- Laizhou Bay

- Liaodong Bay

+ Central Bohai Sea

$\times$ Bohai Strait

Fig. 1. Map of the Bohai Sea showing the surrounding estuaries and sampling sites

were immediately transferred to clean plastic closure pockets, chilled to near freezing, transported to the laboratory, and stored at $-20^{\circ} \mathrm{C}$ in the dark. Before extraction, the samples were freeze-dried, large calcareous debris and rocks and plant fragments were removed, and the samples were ground with an agate mortar and homogenized by sieving through a $0.15-\mathrm{mm}$ mesh.

Sample preparation and antibiotics analysis were based on previously developed methods (Huang et al., 2013). The 17 target veterinary antibiotics belong to four different classes of compound: (1) four tetracyclines comprising tetracycline (TC), oxytetracycline (OTC), chlortetracycline (CTC), and doxycycline (DOC); (2) eight sulfonamides comprising sulfadiazine (SDZ), sulfamethoxazole (SMX), sulfamethazine (SMZ), sulfamonomethoxine (SMM), sulfachinoxalin (SCX), sulfadimethoxine (SDM), sulfameter (SM), and sulfaclozine (SCZ); (3) the four fluoroquinolones norfloxacin (NFC), ofloxacin (OFC), ciprofloxacin
(CFC), and enrofloxacin (EFC), and (4) the one macrolide roxithromycin (RTM). Four isotope-labelled antibiotics consisting of tetracycline-D6, enrofloxacin-D5, sulfamethazine-D4, and sulfadimethoxine-D6 and demeclocycline were selected as internal standards. All target compounds were simultaneously extracted with $\mathrm{Mg}\left(\mathrm{NO}_{3}\right)_{2}-\mathrm{NH}_{3} \cdot \mathrm{H}_{2} \mathrm{O}$ solution coupled with ethylenediaminetetraacetic acid-sodium perborate (EDTA-SPB) at $3: 1(\mathrm{v} / \mathrm{v})$. The $\mathrm{Mg}\left(\mathrm{NO}_{3}\right)_{2}-\mathrm{NH}_{3} \cdot \mathrm{H}_{2} \mathrm{O}$ solution was prepared by mixing the $50 \% \mathrm{Mg}\left(\mathrm{NO}_{3}\right)_{2}$ and $2.5 \% \mathrm{NH}_{3} \cdot \mathrm{H}_{2} \mathrm{O}$ at $96: 4(\mathrm{v} / \mathrm{v})$. The SPB solution was prepared by dissolving $10.56 \mathrm{~g}$ of $\mathrm{NaH}_{2} \mathrm{PO}_{4}$ and $0.82 \mathrm{~mL}$ of $\mathrm{H}_{3} \mathrm{PO}_{4}$ to $1 \mathrm{~L}$ with ultrapure water. The EDTA-SPB (pH 4$)$ mixture was obtained by dissolving $80.0 \mathrm{~g}$ of $\mathrm{Na}_{2}$ EDTA to $1 \mathrm{~L}$ in SPB. The $2.5000( \pm 0.0005) \mathrm{g}$ aliquots of sediment sample spiked with internal standards ( $100.0 \mu \mathrm{g} \mathrm{kg}^{-1}$ ) were extracted ultrasonically three times using $20 \mathrm{~mL}$ extraction solvent for the first extraction and $10 \mathrm{~mL}$ for each of the remaining two. All the $40 \mathrm{~mL}$ extracts were purified and 
concentrated through an oasis hydrophilic-lipophilic balance (HLB) cartridge. Methanol ( $10 \mathrm{~mL}$, containing $0.1 \%$ formic acid) was used to elute the target compounds from the HLB cartridge. The target antibiotics were analyzed by liquid chromatography-electrospray ionization tandem mass spectrometry (LC-ESI-MS/MS) with a Shimadzu LC-20AD and triple quadrupole mass spectrometer (API 3200, AB Sciex, Framingham, MA). Separations were performed on a Kromasil C18 column ( $5 \mu \mathrm{m}, 250 \times 4.6 \mathrm{~mm}$, Akzo Nobel, Sweden) at a constant temperature of $35^{\circ} \mathrm{C}$. The details of the gradient elution program and the optimized MS operating parameters of the antibiotics are described by Huang et al. (2013). Quantification was performed by internal standard calibration. The recoveries of the target compounds were checked by spiking with standards of $50.0,100.0$, and $200.0 \mu \mathrm{g} \mathrm{kg}^{-1}$ with three replicates $(\mathrm{n}=3)$ of each. The mean recoveries and relative standard deviation of all the target antibiotics in the sediments ranged from $73.2 \%$ to $127.2 \%$ and $2.0 \%$ to $11.0 \%$ on average, respectively (Table 1 ). Method blanks showed no detectable amounts of the analytes. The calculations of the limit of detection (LOD), limit of quantification (LOQ), and method detection limit (MDL) are described by Zhang et al. (2015a). The LOD and LOQ ranged from 0.09 to $3.16 \mu \mathrm{g} \mathrm{L}^{-1}$ and 0.49 to $10.5 \mu \mathrm{g} \mathrm{L}^{-1}$, respectively (Table 1). A total of 9 out of the 17 antibiotics were detected at least once in the sediment samples. None of the eight sulfonamides was detected at any of the sampling sites. In contrast, all four FQs were detected in the sediment samples (Table 2). OFC had the highest detection frequency both in marine and estuarine sediments among the four FQs, followed by NFC, EFC and CFC. However, the detection frequencies of the TCs were different between the marine and estuarine sediments. OTC and CTC were the only two detectable TCs in the marine sediments and both had a detection frequency of $<10 \%$. All four TCs were detected in the estuarine sediments and OTC had the highest detection frequency of $54.2 \%$. RTM was detected only in the estuarine sediment as with TC and DOC. The concentrations of all the detectable antibiotics ranged from 0.2 to $4695 \mu \mathrm{g} \mathrm{kg}{ }^{-1}$. The average concentrations of the detectable antibiotics were higher in the estuarine sediments than in the marine sediments. The highest concentration of antibiotics (OTC) was detected in estuarine sediment from the Ziya New River. TCs had higher average and maximum concentrations than the other three types of antibiotic in general. Particularly, the concentration of DOC was high in all the detected samples although the detection frequency was much lower than that of most other antibiotics. The concentrations of the veterinary antibiotics in the estuarine sediments of the Bohai Sea are comparable to results reported from other study areas (Lalumera et al., 2004; Le and Munekage, 2004) as shown in Table 3. The average concentrations of OTC, TC and EFC were generally higher in the present study area than most other study areas. This implies a
Table 2

Summary of the antibiotics concentrations and detection frequencies in the surface sediments of the Bohai Sea and surrounding estuaries $\left(\mu \mathrm{gg}^{-1}\right)$.

\begin{tabular}{|c|c|c|c|c|c|c|c|c|}
\hline & \multicolumn{4}{|c|}{ Marine sediments $(\mathrm{n}=104)$} & \multicolumn{4}{|c|}{ Estuarine sediments $(\mathrm{n}=35)$} \\
\hline & Mean & Min. & Max. & $\mathrm{DF}(\%)$ & Mean & Min. & Max. & $\mathrm{DF}(\%)$ \\
\hline NFC & 2.5 & 1.2 & 6.4 & 14.5 & 15.1 & 1.8 & 66.6 & 45.7 \\
\hline OFC & 1.5 & 0.2 & 6.0 & 22.3 & 7.6 & 0.6 & 42.1 & 71.4 \\
\hline CFC & 4.4 & 2.4 & 9.8 & 6.8 & 12.9 & 2.7 & 47.9 & 28.6 \\
\hline EFC & 2.0 & 0.9 & 5.7 & 14.5 & 19.9 & 0.9 & 252.4 & 51.4 \\
\hline TC & - & - & - & 0 & 25.3 & 1.9 & 126.1 & 11.4 \\
\hline OTC & 9.4 & 1.6 & 48.4 & 9.7 & 268.8 & 2.2 & 4695 & 54.2 \\
\hline СТC & 9.1 & 9.1 & 9.1 & 1.0 & 11.2 & 11.2 & 11.2 & 2.9 \\
\hline DOC & - & - & - & 0 & 110.8 & 106.4 & 115.2 & 5.7 \\
\hline RTM & - & - & - & 0 & 2.5 & 1.9 & 3.5 & 8.5 \\
\hline
\end{tabular}

Note: Min., Max. and DF denote minimum concentration, maximum concentration and detectable frequency, respectively; n denotes sample numbers.

large impact of antibiotics consumption in the aquaculture industry in this area (Jia et al., 2011; Xu et al., 2007). In contrast, the average concentrations of CFC and RTM were lower than reported from other studies.

High spatial heterogeneity of the antibiotics was observed in both marine and estuarine sediments (Fig. 2). A relatively high detection frequency and concentration of FQs occurred in the sediments of Bohai Bay and Laizhou Bay and its surrounding estuaries. However, almost no antibiotics were detected in the marine sediments from Liaodong Bay, in contrast to the high antibiotic concentrations found in the surrounding estuaries. Sediment samples with high concentrations of EFC and CFC in Laizhou Bay were found adjacent to the estuaries of the Wanghe River and the Yellow River. This spatial distribution implies a contribution of terrestrial sources to the antibiotics contamination of the marine sediments. A similar spatial distribution was also found in Bohai Bay and the antibiotics sources were likely associated with the discharge of domestic and agricultural wastewaters (Jiang et al., 2011). A high impact of terrestrial sources was also found in the Bohai Strait and outside the Bohai Sea where higher antibiotics concentrations occurred close to the coastal land. In contrast, the sediments located in the central part of the Bohai Sea were generally characterized by lower concentrations of antibiotics. Similar spatial distributions of FQs have been observed in the surface water of the Bohai Sea (Jia et al., 2011; Zhang et al., 2012; Zou et al., 2011) and the Yellow Sea (Zhang et al., 2013).

All the antibiotics detected together with sediment properties (total organic carbon content (TOC), clay content (CLAY), C/N ratio (C:N)) and the $\mathrm{pH}$ and salt content of the marine water were incorporated into the principal component analysis (PCA). The TCs and FQs were separated

Table 1

Relative recoveries, limits of detection (LOD), limits of quantification (LOQ) and method detection limits (MDL) of the analysis of antibiotics in sediments.

\begin{tabular}{|c|c|c|c|c|c|c|}
\hline Compound & Abbr. & Internal standard & Recovery \% & $\mathrm{LOD}\left(\mu \mathrm{g} \mathrm{L}^{-1}\right)$ & $\mathrm{LOQ}\left(\mu \mathrm{g} \mathrm{L}^{-1}\right)$ & $\mathrm{MDL}\left(\mu \mathrm{kg}^{-1}\right)$ \\
\hline Tetracycline & $\mathrm{TC}$ & Tetracycline-D6 & $101.0 \pm 6.1$ & 0.52 & 1.74 & 2.1 \\
\hline Oxytetracycline & OTC & Tetracycline-D6 & $115.6 \pm 11.0$ & 0.44 & 1.48 & 5.3 \\
\hline Chlortetracycline & CTC & Tetracycline-D6 & $127.2 \pm 9.0$ & 2.29 & 7.62 & 4.2 \\
\hline Doxycycline & DOC & Tetracycline-D6 & $102.8 \pm 4.0$ & 3.16 & 10.5 & 8.5 \\
\hline Sulfadiazine & SDZ & Sulfamethazine-D4 & $103.7 \pm 4.3$ & 0.29 & 0.95 & 2.1 \\
\hline Sulfamethoxazole & SMX & Sulfamethazine-D4 & $115.4 \pm 4.2$ & 0.35 & 1.18 & 3.0 \\
\hline Sulfamethazine & SMZ & Sulfamethazine-D4 & $99.7 \pm 4.3$ & 0.77 & 2.58 & 2.8 \\
\hline Sulfamonomethoxine & SMM & Sulfamethazine-D4 & $113.3 \pm 2.4$ & 0.22 & 0.74 & 1.8 \\
\hline Sulfachinoxalin & SCX & Sulfadimethoxine-D6 & $90.7 \pm 2.9$ & 0.15 & 0.49 & 1.5 \\
\hline Sulfadimethoxine & SDM & Sulfadimethoxine-D6 & $101.9 \pm 2.6$ & 0.15 & 0.49 & 0.5 \\
\hline Sulfameter & SM & Sulfadimethoxine-D6 & $98.8 \pm 2.0$ & 0.22 & 0.74 & 1.4 \\
\hline Sulfaclozine & $\mathrm{SCZ}$ & Sulfadimethoxine-D6 & $103.5 \pm 3.0$ & 0.39 & 1.31 & 1.8 \\
\hline Norfloxacin & NFC & Enrofloxacin-D5 & $101.1 \pm 9.7$ & 0.41 & 1.38 & 4.2 \\
\hline Ofloxacin & OFC & Enrofloxacin-D5 & $73.2 \pm 9.3$ & 0.16 & 0.54 & 5.8 \\
\hline Ciprofloxacin & CFC & Enrofloxacin-D5 & $115.7 \pm 9.3$ & 0.73 & 2.42 & 14.1 \\
\hline Enrofloxacin & $\mathrm{EFC}$ & Enrofloxacin-D5 & $91.6 \pm 5.7$ & 0.26 & 0.87 & 7.9 \\
\hline Roxithromycin & RTM & Enrofloxacin-D5 & $76.2 \pm 6.7$ & 0.09 & 1.53 & 7.0 \\
\hline
\end{tabular}


Table 3

Comparison of the antibiotics levels in the riverine sediments among the different study areas $\left(\mu \mathrm{gg}^{-1}\right)$.

\begin{tabular}{|c|c|c|c|c|c|c|c|c|}
\hline Study area & OTC & $\mathrm{TC}$ & NFC & OFC & CFC & EFC & RTM & Reference \\
\hline Estuaries of the Bohai Sea, Chinab & $268.8(4695)$ & $25.3(126.1)$ & $15.1(66.6)$ & $7.6(42.1)$ & $12.9(47.9)$ & $19.9(252)$ & $2.5(3.5)$ & This study \\
\hline Yellow River, China ${ }^{\mathrm{b}}$ & na (184) & na $(18)$ & $8.34(141)$ & $3.07(123)$ & na $(32.8)$ & & na $(6.8)$ & Zhou et al. (2011) \\
\hline Haihe River, China ${ }^{a}$ & $2.52(422)$ & $2.0(135)$ & $32.0(5770)$ & $10.3(653)$ & $16.0(1290)$ & $1.6(298)$ & $2.29(11.7)$ & Zhou et al. (2011) \\
\hline Haihe River, China ${ }^{c}$ & 14.47 & 17.7 & & & 41.99 & & 21.05 & Xu et al. (2010) \\
\hline Liaohe River, China $^{a}$ & $2.34(652)$ & na (4.82) & $3.32(176)$ & $3.56(50.5)$ & na (28.7) & na (5.82) & $5.51(29.6)$ & Zhou et al. (2011) \\
\hline Pearl River, China ${ }^{a}$ & $7.15(196)$ & $4.0(72.6)$ & $88.0(1120)$ & $156(1560)$ & $21.8(197)$ & & nd & Yang et al. (2010) \\
\hline Pearl River Estuary, China ${ }^{\mathrm{c}}$ & & 15.52 & 85.25 & 1.79 & 10.05 & 15.52 & & Liang et al. (2013) \\
\hline Nanming River, China ${ }^{c}$ & 335 & 312 & & & & & & Liu et al. (2009) \\
\hline Jiulongjiang River, China ${ }^{\mathrm{b}}$ & na $(10,364)$ & na (7614) & & & & & na (5622) & Zhang et al. (2011) \\
\hline Wangyang River, China ${ }^{a}$ & $604(162,673)$ & $40(16,799)$ & $29.8(801.3)$ & $23.2(370.6)$ & $13.1(2118)$ & $6.2(82.1)$ & & Jiang et al. (2014) \\
\hline Oglio River, Italy & $56.28(246.3)$ & & $0.6(1.1)$ & & & & & Lalumera et al. (2004) \\
\hline Ticino River, Switzerland ${ }^{\mathrm{b}}$ & $0.69(4.2)$ & & $30.16(578.8)$ & & & & $37.7(2581)$ & Lalumera et al. (2004) \\
\hline Cache La Poudre River, USA ${ }^{\mathrm{b}}$ & 56.28 (na) & $17.9(102)$ & & & & & & Kim and Carlson (2007) \\
\hline Cache La Poudre River, USA ${ }^{\mathrm{a}}$ & $7.6(56.1)$ & $8.55(102)$ & & & & & $1.9(5.9)$ & Pei et al. (2006) \\
\hline
\end{tabular}

nd: not detected, na: not available.

a Data presented are median concentrations (maximum concentrations), $\mu \mathrm{g} \mathrm{kg}{ }^{-1}$.

b Data presented are mean concentrations (maximum concentrations), $\mu \mathrm{g} \mathrm{kg}{ }^{-1}$.

c Data presented are mean concentrations, $\mu \mathrm{kg}^{-1}$.

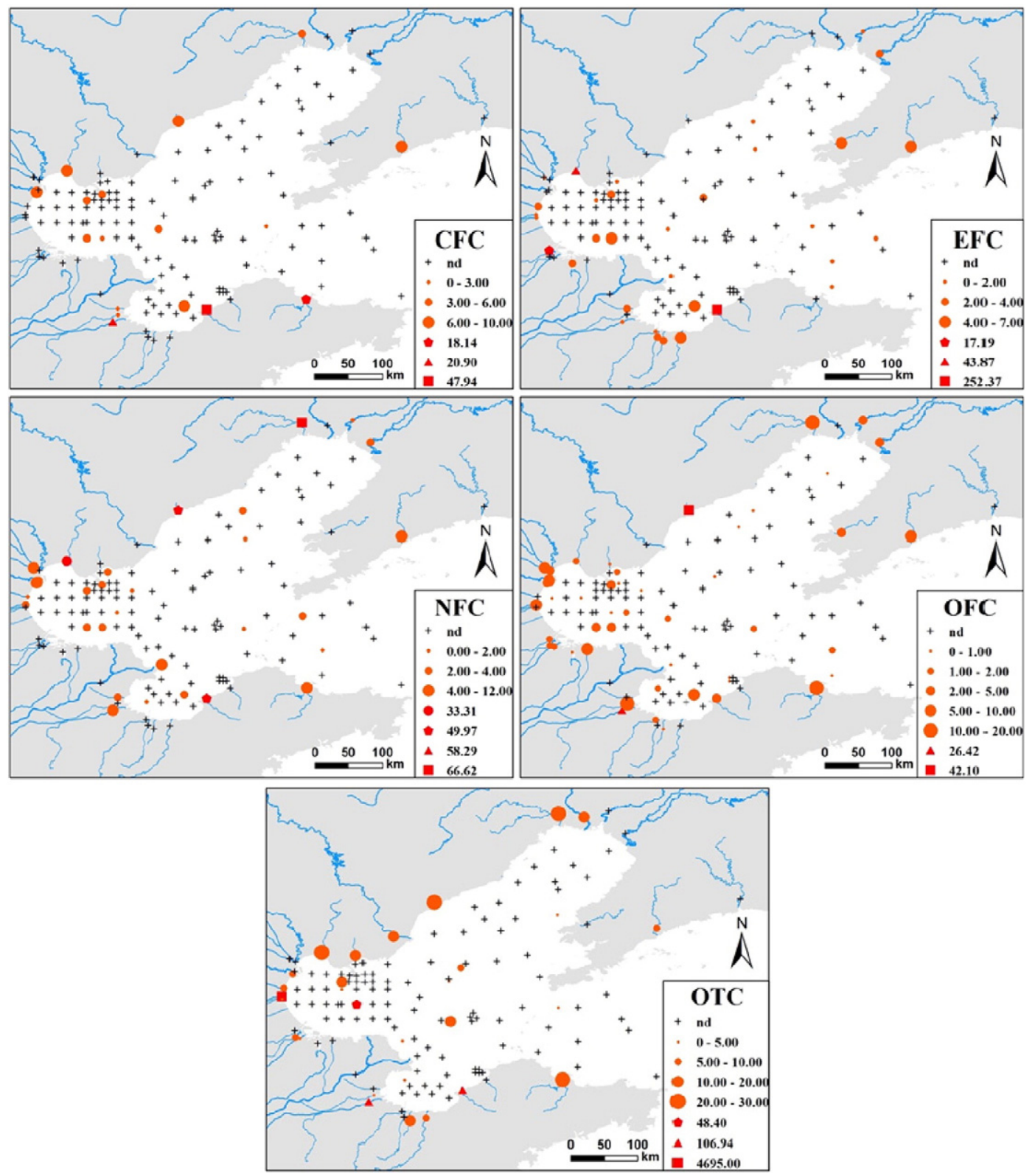

Fig. 2. Spatial distribution of the antibiotics detected in the sediments of the Bohai Sea and surrounding estuaries. 

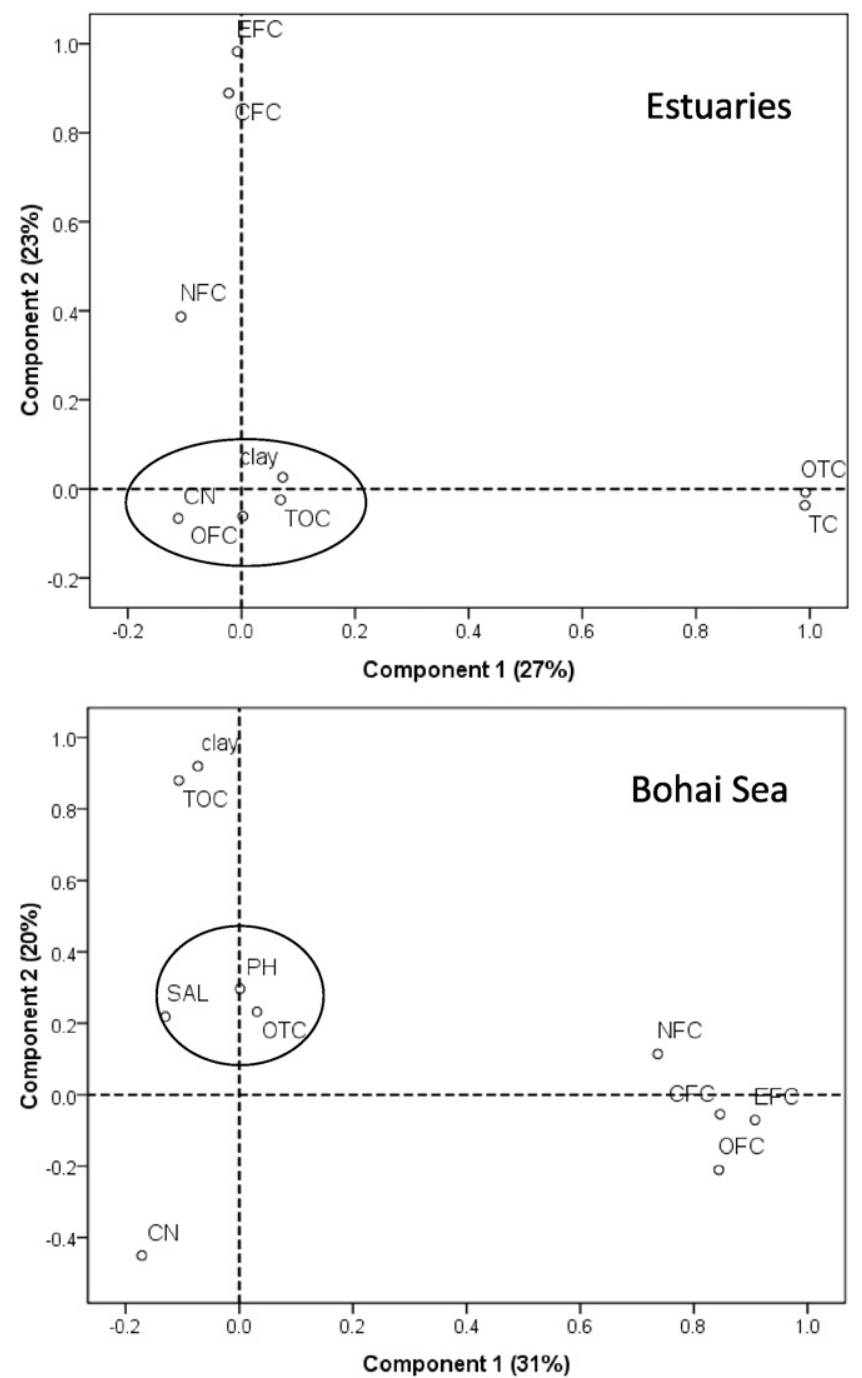

Fig. 3. Principal component analysis of the antibiotic concentrations and physicochemical properties of the sediments in the Bohai Sea and the surrounding estuaries (TOC: total organic carbon, $\mathrm{SAL}$ : salt content, $\mathrm{CN}$ : C/N ratio).

clearly on the score plots of both estuarine and marine sediments. Differences were observed in the groups of antibiotics in relation to sediment properties. In the case of estuarine sediments, OFC was grouped with TOC, and clay content with C/N ratio (Fig. 3), which implies effects of the sediment properties on the retention of OFC (Peng et al., 2015). In the case of the marine sediments, OTC was grouped with ocean water properties ( $\mathrm{pH}$ and salt content) (Gothwal and Shashidhar, 2015) rather than sediment properties (Fig. 3).

The risk quotient (RQ) values were calculated using the following equation (Bodar et al., 2003):

$\mathrm{RQ}=\mathrm{MEC} / \mathrm{PNEC}$

where MEC and PNEC denote the measured environmental concentration and predicted no-effect concentration, respectively. Most of the PNEC values are available for the antibiotics in water. The calculation was therefore performed by converting the measured antibiotics concentrations in the sediments into their corresponding pore water concentrations $\left(C_{\text {pore water }}\right)$ using following equation (Zhao et al., 2010):

$\mathrm{C}_{\text {pore water }}=\frac{1000 \times \mathrm{C}_{\mathrm{S}}}{\mathrm{K}_{\mathrm{OC}}} \times \%$ total organic carbon
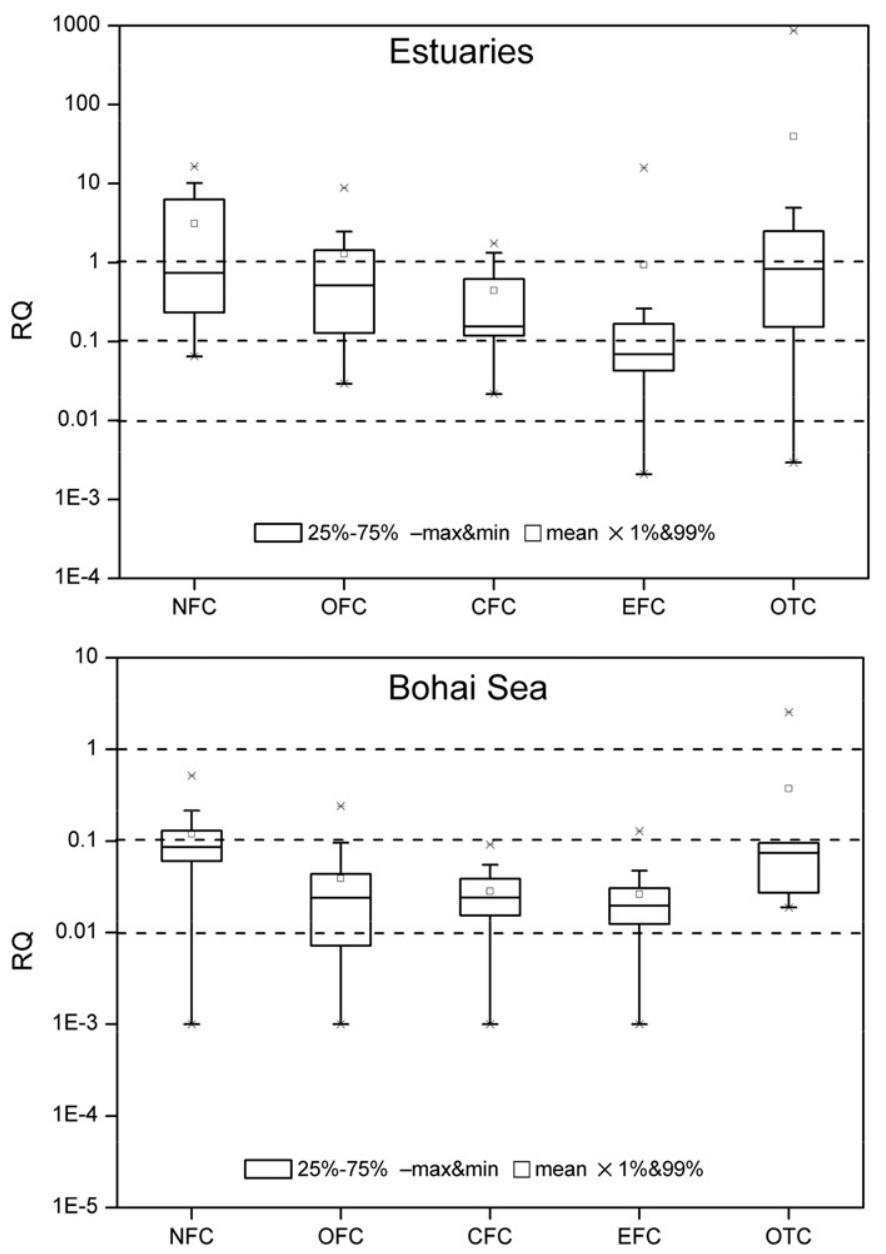

Fig. 4. Boxplots of the calculated risk quotients (RQs) of the antibiotics detected in the Bohai Sea and surrounding estuaries.

where $\mathrm{K}_{\mathrm{OC}}$ is the organic carbon normalized partitioning coefficient and $\mathrm{C}_{\mathrm{S}}\left(\mu \mathrm{g} \mathrm{kg}{ }^{-1}\right)$ is the measured antibiotics concentrations in the sediment. The subsequent calculation of RQs in the sediments was as same as Eq. (1). The PNEC values were calculated based on the method recommended by the European Technical Guidance Document (TGD) in which PNEC was obtained from toxicity data of $\mathrm{EC}_{50}$ or $\mathrm{LC}_{50}$ divided by a fixed assessment factor (from 1000 to 10 depending on the ecotoxicological tests conducted) (Bodar et al., 2003). The aquatic toxicity data for the target antibiotics was obtained from the literature in order to calculate the PNEC (Boxall et al., 2004; Halling-Sørensen, 2000; Isidori et al., 2005; Kolar et al., 2014; Park and Choi, 2008; Robinson et al., 2005).

The risk was classified into three levels based on the RQ values, namely low risk at RQs ranging from 0.01 to 0.1 , medium risk at RQs of $0.1-1$ and high risk at RQs $>1$ (Hernando et al., 2006). The box plot of RQs indicates that the estuarine sediments presented a higher potential ecological antibiotics risk than the marine sediments in general (Fig. 4). Similar results have also been reported from surface waters of Laizhou Bay (Zhang et al., 2012), Germany (Kümmerer and Henninger, 2003), Wanghe River (Jiang et al., 2014), the Pearl River system (Yang et al., 2010) and Korea (Lee et al., 2008). Antibiotics such as NFC, OTC and OFC may show high risk to sensitive aquatic organisms (Daphnia magna) in some estuarine sediment samples and the highest RQ of OTC was 863.4, a high value which should be of great concern. In the case of marine sediments, NFC and OTC should be of concern mainly in the Bohai Sea because the average values of the RQs of NFC and OTC were at the medium and high risk levels, respectively. 


\section{Acknowledgements}

This research was supported financially by the National Natural Science Foundation of China (41371313 and 41230858) and WPOS Project (no. XDA11020402).

\section{References}

Bodar, C., Berthault, F., De Bruijn, J., Van Leeuwen, C., Pronk, M., Vermeire, T., 2003. Evaluation of EU risk assessments existing chemicals (EC Regulation 793/93). Chemosphere 53, 1039-1047.

Boxall, A., Fogg, L., Blackwell, P., Blackwell, P., Kay, P., Pemberton, E., Croxford, A., 2004. Veterinary Medicines in the Environment, Reviews of Environmental Contamination and Toxicology. Springer, pp. 1-91.

Bu, Q., Wang, B., Huang, J., Deng, S., Yu, G., 2013. Pharmaceuticals and personal care products in the aquatic environment in China: a review. J. Hazard. Mater. 262, 189-211.

Eguchi, K., Nagase, H., Ozawa, M., Endoh, Y.S., Goto, K., Hirata, K., Miyamoto, K., Yoshimura, H., 2004. Evaluation of antimicrobial agents for veterinary use in the ecotoxicity test using microalgae. Chemosphere 57, 1733-1738.

Gothwal, R., Shashidhar, T., 2015. Antibiotic pollution in the environment: a review. Clean-Soil, Air, Water 43, 479-489.

Gulkowska, A., He, Y., So, M.K., Yeung, L.W.Y., Leung, H.W., Giesy, J.P., Lam, P.K.S., Martin, M., Richardson, B.J., 2007. The occurrence of selected antibiotics in Hong Kong coastal waters. Mar. Pollut. Bull. 54, 1287-1293.

Halling-Sørensen, B., 2000. Algal toxicity of antibacterial agents used in intensive farming. Chemosphere 40, 731-739.

Hernando, M.D., Mezcua, M., Fernández-Alba, A., Barceló, D., 2006. Environmental risk assessment of pharmaceutical residues in wastewater effluents, surface waters and sediments. Talanta 69, 334-342.

Huang, Y.J., Cheng, M., Li, W., Wu, L., Chen, Y., Luo, Y., Christie, P., Zhang, H., 2013. Simultaneous extraction of four classes of antibiotics in soil, manure and sewage sludge and analysis by liquid chromatography-tandem mass spectrometry with the isotope-labelled internal standard method. Anal. Methods 5, 3721-3731.

Isidori, M., Lavorgna, M., Nardelli, A., Pascarella, L., Parrella, A., 2005. Toxic and genotoxic evaluation of six antibiotics on non-target organisms. Sci. Total Environ. 346, 87-98.

Jia, A., Hu, J., Wu, X., Peng, H., Wu, S., Dong, Z., 2011. Occurrence and source apportionment of sulfonamides and their metabolites in Liaodong Bay and the adjacent Liao River basin, North China. Environ. Toxicol. Chem. 30, 1252-1260.

Jiang, L., Hu, X., Yin, D., Zhang, H., Yu, Z., 2011. Occurrence, distribution and seasonal variation of antibiotics in the Huangpu River, Shanghai, China. Chemosphere 82, 822-828.

Jiang, Y.H., Li, M.X., Guo, C.S., An, D., Xu, J., Zhang, Y., Xi, B.D., 2014. Distribution and ecological risk of antibiotics in a typical effluent-receiving river (Wangyang River) in north China. Chemosphere 112, 267-274.

Jun, Z.B.h.Y.w.W.L., 2007. Historical evolvement trends of nutrients in waters of Bohai Bay from 1985 to 2003. Environ. Sci. 28, 3.

Kim, S.C., Carlson, K., 2007. Temporal and spatial trends in the occurrence of human and veterinary antibiotics in aqueous and river sediment matrices. Environmental science \& technology 41, 50-57.

Kolar, B., Arnuš, L., Jeretin, B., Gutmaher, A., Drobne, D., Durjava, M.K., 2014. The toxic effect of oxytetracycline and trimethoprim in the aquatic environment. Chemosphere $115,75-80$.

Kümmerer, K., 2004. Resistance in the environment. J. Antimicrob. Chemother. 54 311-320.

Kümmerer, K., 2009. Antibiotics in the aquatic environment - a review - part I. Chemosphere 75, 417-434.

Kümmerer, K., Henninger, A., 2003. Promoting resistance by the emission of antibiotics from hospitals and households into effluent. Clin. Microbiol. Infect. 9, 1203-1214.

Lalumera, G.M., Calamari, D., Galli, P., Castiglioni, S., Crosa, G., Fanelli, R., 2004. Preliminary investigation on the environmental occurrence and effects of antibiotics used in aquaculture in Italy. Chemosphere 54, 661-668.

Le, T.X., Munekage, Y., 2004. Residues of selected antibiotics in water and mud from shrimp ponds in mangrove areas in Viet Nam. Mar. Pollut. Bull. 49, 922-929.

Lee, Y.-J., Lee, S.-E., Lee, D.S., Kim, Y.-H., 2008. Risk assessment of human antibiotics in Korean aquatic environment. Environ. Toxicol. Pharmacol. 26, 216-221.

Li, B.Y., Li, g., Gao, C.Y., 2014. Analysis of comparative advantage of the main aquaculture products in Bohai Rim. Chin. Agric. Sci. Bull. 30.
Liang, X., Shi, Z., Huang, X., 2013. Occurrence of antibiotics in typical aquaculture of the Pearl River Estuary. Ecol Environ Sci 22, 304-310.

Liu, H., Zhang, G., Liu, C.Q., Li, L., Xiang, M., 2009. The occurrence of chloramphenicol and tetracyclines in municipal sewage and the Nanming River, Guiyang City, China. Journal of Environmental Monitoring 11, 1199-1205.

Mao, T.Y., Dai, M.X., Peng, S.T., Li, G.L., 2009. Temporal-spatial variation trend analysis of heavy metals $(\mathrm{Cu}, \mathrm{Zn}, \mathrm{Pb}, \mathrm{Cd}, \mathrm{Hg})$ in Bohai Bay in 10 years. J. Tianjin Univ. 42 817-825.

Martins, A.F., Vasconcelos, T.G., Henriques, D.M., Frank, C.d.S., König, A., Kümmerer, K., 2008. Concentration of ciprofloxacin in Brazilian hospital effluent and preliminary risk assessment: a case study. Clean-Soil, Air, Water 36, 264-269.

Minh, T.B., Leung, H.W., Loi, I.H., Chan, W.H., So, M.K., Mao, J.Q., Choi, D., Lam, J.C.W., Zheng, G., Martin, M., Lee, J.H.W., Lam, P.K.S., Richardson, B.J., 2009. Antibiotics in the Hong Kong metropolitan area: ubiquitous distribution and fate in Victoria Harbour. Mar. Pollut. Bull. 58, 1052-1062.

Park, S., Choi, K., 2008. Hazard assessment of commonly used agricultural antibiotics on aquatic ecosystems. Ecotoxicology 17, 526-538.

Pei, R., Kim, S.C., Carlson, K.H., Pruden, A., 2006. Effect of river landscape on the sediment concentrations of antibiotics and corresponding antibiotic resistance genes (ARG). Water Research 40, 2427-2435.

Peng, H.B., Liang, N., Li, H., Chen, F.Y., Zhang, D., Pan, B., Xing, B.S., 2015. Contribution of coated humic acids calculated through their surface coverage on nano iron oxides for ofloxacin and norfloxacin sorption. Environ. Pollut. 204, 191-198.

Robinson, A.A., Belden, J.B., Lydy, M.J., 2005. Toxicity of fluoroquinolone antibiotics to aquatic organisms. Environ. Toxicol. Chem. 24, 423-430.

Sarmah, A.K., Meyer, M.T., Boxall, A.B.A., 2006. A global perspective on the use, sales, exposure pathways, occurrence, fate and effects of veterinary antibiotics (VAs) in the environment. Chemosphere 65, 725-759.

Wang, C., Wang, X., 2007. Spatial distribution of dissolved $\mathrm{Pb}, \mathrm{Hg}, \mathrm{Cd}, \mathrm{Cu}$ and as in the Bohai Sea. J. Environ. Sci. 19, 1061-1066.

Wang, S.L., Wang, H., 2015. Adsorption behavior of antibiotic in soil environment: a critical review. Front. Environ. Sci. Eng. 9, 565-574.

Wille, K., Noppe, H., Verheyden, K., Bussche, J.V., De Wulf, E., Van Caeter, P., Janssen, C.R. De Brabander, H.F., Vanhaecke, L., 2010. Validation and application of an LC-MS/MS method for the simultaneous quantification of 13 pharmaceuticals in seawater Anal. Bioanal. Chem. 397, 1797-1808.

Xu, W.H., Zhang, G., Zou, S.C., Li, X.D., Liu, Y.C., 2007. Determination of selected antibiotics in the Victoria Harbour and the Pearl River, South China using high-performance liquid chromatography-electrospray ionization tandem mass spectrometry. Environ. Pollut. 145, 672-679.

Xu, L., Luo, Y., Xu, B.-J., 2010. Simultaneous Determination for 12 Antibiotics in Sediments of Haihe River by HPLC-MS/MS Method [J]. Journal of Instrumental Analysis 1, 005.

Yang J.F., Ying G.G., Zhao, J.. Tao, R., Su, H.C., Chen, F., 2010. Simultaneous determination of four classes of antibiotics in sediments of the Pearl Rivers using RRLC-MS/MS. Sci. Total Environ. 408, 3424-3432.

Zhang, D.D., Lin, L.F., Luo, Z.X., Yan, C.Z., Zhang, X., 2011. Occurrence of selected antibiotics in Jiulongjiang River in various seasons, South China. Journal of Environmental Monitoring 13, 1953-1960.

Zhang, R.J., Zhang, G., Zheng, Q., Tang, J.H., Chen, Y.J., Xu, W.h., Zou, Y.D., Chen, X.X., 2012 Occurrence and risks of antibiotics in the Laizhou Bay, China: impacts of river discharge. Ecotoxicol. Environ. Saf. 80, 208-215.

Zhang, R.J., Tang, J., Li, J., Cheng, Z., Chaemfa, C., Liu, D., Zheng, Q., Song, M., Luo, C., Zhang G., 2013. Occurrence and risks of antibiotics in the coastal aquatic environment of the Yellow Sea, North China. Sci. Total Environ. 450-451, 197-204.

Zhang, H.B., Luo, Y.M., Wu, L.H., Huang, Y.J., Christie, P., 2015a. Residues and potential ecological risks of veterinary antibiotics in manures and composts associated with protected vegetable farming. Environ. Sci. Pollut. Res. 22, 5908-5918.

Zhang, Q.Q., Ying, G.G., Pan, C.G., Liu, Y.S., Zhao, J.L., 2015b. A comprehensive evaluation of antibiotics emission and fate in the river basins of China: source analysis, multimedia modelling, and linkage to bacterial resistance. Environ. Sci. Technol.

Zhao, L., Dong, Y.H., Wang, H., 2010. Residues of veterinary antibiotics in manures from feedlot livestock in eight provinces of China. Sci. Total Environ. 408, 1069-1075.

Zhou, L.J., Ying, G.G., Zhao, J.L., Yang, J.F., Wang, L., Yang, B., Liu, S., 2011. Trends in the occurrence of human and veterinary antibiotics in the sediments of the Yellow River, Hai River and Liao River in northern China. Environmental Pollution 159, 1877-1885.

Zou, S.C., Xu, W.H., Zhang, R.J., Tang, J.H., Chen, Y.J., Zhang, G., 2011. Occurrence and distribution of antibiotics in coastal water of the Bohai Bay, China: impacts of river discharge and aquaculture activities. Environ. Pollut. 159, 2913-2920. 